\title{
sciendo
}

Current Issues in Pharmacy and Medical Sciences

Formerly ANNALES UNIVERSITATIS MARIAE CURIE-SKLODOWSKA, SECTIO DDD, PHARMACIA

\section{Effect of early amniotomy on labor outcome in nulliparous women: a randomized clinical trial}

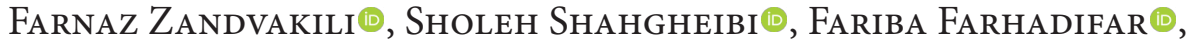 \\ Fariba Seyedoshohadaei ${ }^{\circledR}$, Ameneh Khalili $^{*}{ }^{\circledR}$
}

Department of Obstetrics and Gynecology, Faculty of Medicine, Kurdistan University of Medical Sciences, Sanandaj, Iran

\begin{tabular}{|c|c|}
\hline ARTICLE INFO & ABSTRACT \\
\hline $\begin{array}{l}\text { Received } 26 \text { January } 2019 \\
\text { Accepted } 27 \text { March } 2019\end{array}$ & $\begin{array}{l}\text { Early amniotomy is one of the main interventions to enhance the labor progress and } \\
\text { prevent dystocia in pregnant women. However, the efficacy of amniotomy has not }\end{array}$ \\
\hline $\begin{array}{l}\text { Keywords: } \\
\text { amniotomy, } \\
\text { Apgar, } \\
\text { labor outcomes, } \\
\text { postpartum haemorrhage. }\end{array}$ & $\begin{array}{l}\text { been approved via labor-related indices and outcomes and has remained a subject for } \\
\text { debate and future research. The present study was conducted to evaluate the effect } \\
\text { of early amniotomy on labor indices and outcomes in nulliparous women. This randomized } \\
\text { clinical trial was performed on } 151 \text { singleton pregnant women who were referred to Besat } \\
\text { Hospital in Sanandaj, Iran, from March } 2016 \text { to March } 2018 \text {. Participants were randomly } \\
\text { divided into an early amniotomy (EA) group and a control group. Duration of the first } \\
\text { and second phases of labor, corioamionit, dystocia rate, Apgar score at the first and fifth } \\
\text { minutes, prolonged labor and post-partum haemorrhage were evaluated and compared } \\
\text { between the two groups. Data were recorded in a checklist and analysed using SPSS } \\
\text { Version } 23 \text {. The p value }<0.05 \text { was considered significant. Results showed that labor indices } \\
\text { such as duration of the first and second phases, Apgar score one and five minutes after } \\
\text { delivery and frequency of prolonged labor, foetal distress and postpartum haemorrhage } \\
\text { were significantly improved in patients of the early amniotomy group, compared with the } \\
\text { control group (p } \leq 0.05 \text { ). Early amniotomy significantly decreased the total labor duration } \\
\text { without significant increase in the rate of maternal and neonatal complications. }\end{array}$ \\
\hline
\end{tabular}

\section{INTRODUCTION}

Labor induction (LI) is planned when the benefits of delivery for fetus and pregnant women are higher than is the continuance of pregnancy. LI is associated with a twofold increase in the caesarean section rate and has an inverse relationship with cervix favorability [1-3]. The intent of induced labor is to deliver healthy babies to healthy mothers with minimum adverse effects [1]. One of the appropriate interventions for achieving healthy delivery is early amniotomy as the elective rupture of fetal membrane in the cervix at dilatation $\leq 4 \mathrm{~cm}$ [2]. Moreover, early amniotomy may reduce prolonged labor and its complications $[4,5]$, as amniotomy during the delivery phase can promote prostaglandin and oxytocin secretion and accelerate delivery in both spontaneous and induced labor [4].

Efficacy of amniotomy has not been approved by means of labor indices and outcomes and has remained as a subject

\footnotetext{
* Corresponding author

e-mail: a.khalili@muk.ac.ir
}

for debate and future research. Although early amniotomy helps in the close monitoring of amniotic fluid, as well as placement of intrauterine catheter [5], it might cause increased fetal heart rate risk abnormality, cord prolapse and infection because of the increased rate of vaginal examination $[6,7]$. Due to vertical transmission of infection, early amniotomy is contraindicated in women with HIV/AIDS infection [5]. While amniotomy is suggested as a component of active management of labor to reduce the caesarean section rate for labor dysfunction [6], its impact on the labor duration has not been studied and approved. Still, some studies reported that early amniotomy could reduce labor duration, lower rate of dystocia and has no effect on other labor indices [8-10]. According to our review of recent literature, currently, there are no recommendations for using early amniotomy in pregnant women, and, thus, there is a need for further research in this subject area. Close monitoring of prolonged pregnancy in nulliparous is very important for determining optimal labor time with least maternal 
and neonatal complications. Therefore, this study was conducted to evaluate the effect of early amniotomy on labor indices and outcomes in nulliparous women.

\section{MATERIALS AND METHODS}

This randomized clinical trial was performed on 151 pregnant women who were referred to Besat Hospital in Sanandaj, Iran from March 2016 to March 2018. All participants signed informed consents. Inclusion criteria were nulliparous pregnant women (older than 41 gestational weeks) vertex position with bishop score more than five. Exclusion criteria were preeclampsia, gestational diabetes, meconium in the amniotic fluid, breech presentation, twin pregnancy and fetal anomalies such as hydrocephaly.

In this study, we defined the active phase of labor as primary cervix dilatation (until four centimeters) and completed the dilatation of the cervix. The second phase of the study was defined as time duration between complete cervix dilatation and neonatal delivery. The prolonged active phase of labor was defined as cervix dilatation less than one centimeter per hour for at least four hours.

Participants were divided into intervention group (early amniotomy) and control group (no- aminotomy) randomly. Duration of active phase and second stage of labor, corioamionit, dystocia rate, Apgar score at the first and fifth minutes, prolonged labor and post-partum haemorrhage were evaluated and compared between two groups. In the EA group $(n=73)$, amniotomy was performed with cervical dilatation less than four centimeters and oxytocin infusion was performed if no efficient contractions occurred one hour after amniotomy. In the control group $(\mathrm{n}=78)$, augmentation with oxytocin was performed for pregnant women with bishop score higher than five. The progress of labor was followed according to the WHO partograph [11]. Regarding the corioamnionitis that was based on clinical diagnostic criteria (painful uterine touch and vaginal discharge) and laboratory diagnosis (CRP, CBC diff), and also to prevent amniotomy complications, we monitored foetuses and their mothers every one hour to control the mother and body temperature.

In the febrile mothers, we performed essential and necessary activities such as antibiotic therapy and laboratory assessment. In pregnancies with the prolonged rupture of membrane, we initiated prophylactic antibiotics.

Data were recorded in a checklist and analysed using SPSS Version 23. Quantitative variables were expressed as mean and standard deviation (mean $\pm \mathrm{SD}$ ), and the qualitative variables were indicated as percentage. To compare quantitative variables, t-test was applied, and for qualitative variables, chi-square test was used. Paired t-test was employed to determine the changes in indices before and after the intervention. The $p$ value $<0.05$ was considered significant.

This study was approved by the Ethics Committee of Kurdistan University of Medical Sciences (IR.MUK. REC.1396/331) and registered at the Iranian Registry of Clinical Trials under IRCT20180830040908N1 code.

\section{RESULTS}

A total of 151 nulliparous women were enrolled in the study and randomly allocated into intervention (early amniotomy) group ( $\mathrm{n}=73)$ and control (no- amniotomy) group $(\mathrm{n}=78)($ Figure 1).

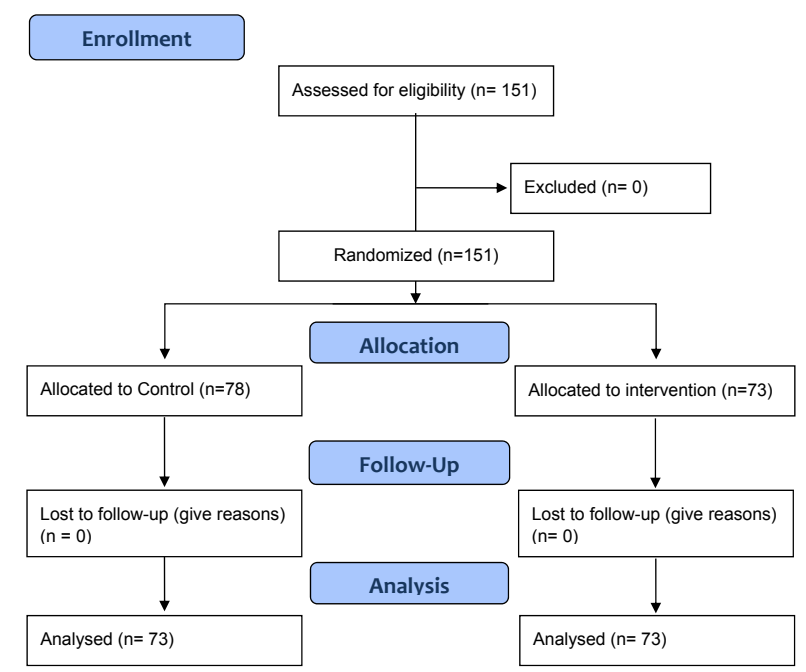

Figure 1. Flow chart of the study

The results showed that the mean and SD of the first labor phase in the intervention and control groups were 124.86 \pm 51.41 and $187.12 \pm 86.12$ minutes, respectively - which was statistically significant $(p=0.001)$. The mean and SD of the second labor phase in the intervention and control groups were $38.77 \pm 15.27$ and $44.62 \pm 14.18$ minutes, respectively - which was also statistically significant $(\mathrm{p}=0.016)$ (Table 1).

Table 1. Comparing the labor outcomes between the study groups

\begin{tabular}{|l|c|c|c|}
\hline \multicolumn{1}{|c|}{ Outcomes } & $\begin{array}{c}\text { Amniotomy group } \\
(\mathrm{n}=78)\end{array}$ & $\begin{array}{c}\text { Control group } \\
(\mathrm{n}=73)\end{array}$ & $p$ value \\
\hline First labor phases & $124.86 \pm 51.41$ & $187.12 \pm 76.57$ & 0.001 \\
\hline Second labor phase & $38.77 \pm 15.27$ & $44.62 \pm 14.18$ & 0.016 \\
\hline Apgar (First) & $8.97 \pm 0.12$ & $8.71 \pm 0.61$ & 0.001 \\
\hline Apgar (Fifth) & $9.98 \pm 0.12$ & $9.97 \pm 0.19$ & 0.35 \\
\hline
\end{tabular}

In this study, 10 prolonged labors were observed, which were all in the control group. Accordingly, the frequency distribution of prolonged labors was significantly higher in the control group than in the early amniotomy group $(p=0.02)$.

Two cases of fetal distress were observed, all of which were in the control group. The frequency distribution of fetal distress was significantly higher in the control group than in the early amniotomy group $(\mathrm{p}=0.17)$.

There were no cases of corioamionit and dystocia among the study participants. Total of 16 post-partum hemorrhage cases were observed, of which two cases $(12.5 \%)$ were in the early amniotomy and 14 cases $(87.5 \%)$ in the control group. There was a significant correlation between incidence of postpartum hemorrhage in two intervention and control groups $(p=0.002)$. 


\section{DISCUSSION}

The aim of this study was to evaluate the effect of early amniotomy on labor indices and outcomes in nulliparous women. The results of our study showed that labor indices such as duration of the first and second phases of labor, Apgar score one and five minutes after delivery and frequency of prolonged labor or fetal distress and postpartum haemorrhage were significantly improved in women of the early amniotomy group, compared with those of the control group. Overall, amniotomy was performed during labor to speed up uterine contraction and shorten labor phases [12]. In our study, we could shorten the labor phases, especially the first phase. The findings of our study were similar to previous studies that reported that early amniotomy could shorten the labor phases for two or even four hours $[13,14]$. Indeed, Li et al. reported a 1.5-hour decrease in the duration of the first labor phase after early amniotomy [15]. In contrast to our findings, Levy et al. and Smyth et al. reported that duration of labor during early amniotomy was not significantly different compared to that reported after late amniotomy [16]. We can explain this difference between different studies that depends on the type of modifications that add to spontaneous delivery in each study. It appears that the length of labor is correlated directly to maternal complications such as chorioamnionitis, postpartum fever and neonatal infection $[17,18]$.

In our study, there were no cases of crioamionit and dystocia among the study participants. In a study by Fraser et al., early amniotomy reduced the occurrence of dystocia [8], while in a study by Ghafarzadeh et al., 10 cases of dystocia in the intervention group and 38 cases in the control group were reported [10].

We must consider shorter duration of labor against both maternal and fetal complications and safety. In most of the similar studies, we observed higher rate of complications in the early amniotomy group compared with other pregnant women [13]. In previous studies, the rate of maternal complications such as chorioamnionitis did not significantly change by using different approaches of amniotomy performance $[14,19]$. It appears that some differences in the rate of chorioamnionitis among pregnant mothers have not significant impact on the increase rate of suspected neonatal sepsis or NICU admission among neonates. However, in most of the developed countries, gynaecologists do not recommend amniotomy to accelerate labor [20,21].

We believe that in some of the developing countries, amniotomy appears to be justified, especially in general hospitals due to lack of medical staff and budget. A close monitoring of patients for a long period is difficult and thus amniotomy might be a proper selection for the control of maternal and neonatal health. Our study had some limitations. Firstly, our study sample size was low and this low sample size decreased the study power and in some situations, we had not sufficient confidence in the reported nonsignificant differences. Secondly, the present study was performed in one clinical center. We assume that multicentral trail with a higher sample size and different frequency of labor situation might have other results.

\section{CONCLUSION}

We found that early amniotomy significantly decreased the total labor duration without significant increase in the rate of maternal and neonatal complications.

\section{ACKNOWLEDGMENTS}

The authors would like to thank all the nurses and midwifes of Besat Hospital, especially those at the gynaecology department, for their contribution to the study. We would like to thank Vice Chancellor for Research of Kurdistan University of Medical Sciences to support this study financially.

\section{ORCID iDs}

Farnaz Zandvakili (1) https://orcid.org/0000-0003-4423-1559 Sholeh Shahgheibi (1)https://orcid.org/0000-0003-1662-5235

Fariba Farhadifar (Dhttps://orcid.org/ 0000-0001-5823-8482

Fariba Seyedoshohadaei

(1D)https://orcid.org/0000-0002-7828-2453

Ameneh Khalili (1)https://orcid.org/ 0000-0001-5707-4762

\section{REFERENCES}

1. Xenakis EM-J, Piper JM, Conway DL, Langer O. Induction of labor in the nineties: conquering the unfavorable cervix. Obstet Gynecol. 1997;90(2):235-9.

2. Vahratian A, Zhang J, Troendle JF, Sciscione AC, Hoffman MK. Labor progression and risk of cesarean delivery in electively induced nulliparas. Obstet Gynecol. 2005;105(4):698-704.

3. Pennell C, Henderson J, O’Neill M, McCleery S, Doherty D, Dickinson J. Induction of labour in nulliparous women with an unfavourable cervix: a randomized controlled trial comparing double and single balloon catheters and PGE2 gel. BJOG: an international journal of obstetrics \& gynaecology. 2009;116(11):1443-52.

4. Chard T, Gibbens G. Spurt release of oxytocin during surgical induction of labor in women. Am J Obstet Gynecol. 1983;147(6): 678-80.

5. Onah LN, Dim CC, Nwagha UI, Ozumba BC. Effect of early amniotomy on the outcome of spontaneous labour: a randomized controlled trial of pregnant women in Enugu, South-east Nigeria. Afr Health Sci. 2015; 15(4):1097-103.

6. Cohain JS. Amniotomy and cord prolapse. Midwifery Today with International Midwife. 2013;108:32-33

7. Goffinct F, Fraser W, Marcoux S, Bréart G, Moutquin JM, Daris M, et al. Early amniotomy increases the frequency of fetal heart rate abnormalities. BJOG: an international journal of obstetrics \& gynaecology. 1997;104(5):548-53.

8. Fraser WD, Marcoux S, Moutquin J-M, Christen A, Group CEAS. Effect of early amniotomy on the risk of dystocia in nulliparous women. N Engl J Med. 1993; 328(16):1145-9.

9. Ajadi M, Kuti O, Orji E, Ogunniyi S, Sule S. The effect of amniotomy on the outcome of spontaneous labour in uncomplicated pregnancy. J Obstet Gynecol. 2006;26(7):631-4.

10. Ghafarzadeh M, Moeininasab S, Namdari M. Effect of early amniotomy on dystocia risk and cesarean delivery in nulliparous women: a randomized clinical trial. Arch Gynecol Obstet. 2015;292(2):321-5.

11. WHO Reproductive Health Library. WHO recommendation on the use of active phase partograph with a four-hour action line for monitoring the progress of labour. (May 2014). The WHO Reproductive Health Library; Geneva: World Health Organization.

12. Fraser WD, Turcot L, Krauss I, Brisson-Carrol G, Smyth R. Amniotomy for shortening spontaneous labour. Cochrane Database Syst Rev. 2000 (1).

13. Mercer BM, McNanley T, O'brien JM, Randal L, Sibai BM. Early versus late amniotomy for labor induction: a randomized trial. Am J Obstet Gynecol. 1995;173(4):1321-5. 
14. Macones GA, Cahill A, Stamilio DM, Odibo AO. The efficacy of early amniotomy in nulliparous labor induction: a randomized controlled trial. Am J Obstet Gynecol. 2012;207(5):403. e1-5.

15. Li N, Wang Y, Zhou H. Effects of routine early amniotomy on labor and health status of foetus and neonate: a meta-analysis. Zhonghua Fu Chan Ke Za Zhi. 2006;41(1):9-16.

16. Levy R, Ferber A, Ben-Arie A, Paz B, Hazan Y, Blickstein I, et al. A randomised comparison of early versus late amniotomy following cervical ripening with a Foley catheter. BJOG: an international journal of obstetrics \& gynaecology. 2002;109(2):168-72.

17. Herbst A, Källén K. Time between membrane rupture and delivery and septicemia in term neonates. Obstet Gynecol. 2007;110(3):612-8.
18. Tran SH, Cheng YW, Kaimal AJ, Caughey AB. Length of rupture of membranes in the setting of premature rupture of membranes at term and infectious maternal morbidity. Am J Obstet Gynecol. 2008;198(6):700. e1-. e5.

19. Lee SM, Lee KA, Lee J, Park C-W, Yoon BH. "Early rupture of membranes" after the spontaneous onset of labor as a risk factor for cesarean delivery. Eur J Obstet Gynecol and Reprod Biol. 2010; 148(2):152-7.

20. Sadler L, Davison T, McCowan L. A randomised controlled trial and meta-analysis of active management of labour. BJOG: an international journal of obstetrics \& gynaecology. 2000;107(7): 909-15.

21. Smyth RM, Markham C, Dowswell T. Amniotomy for shortening spontaneous labour. Cochrane Database Syst Rev. 2013(6). 